Bull. Mater. Sci., Vol. 17, No. 6, November 1994, pp. 1181-1196. (C) Printed in India.

\title{
Technology development and applications of composites at HAL
}

\author{
C G KRISHNADAS NAIR \\ Hindustan Aeronautics Limited, Bangalore 560017 , India
}

\begin{abstract}
Composite materials for aerospace applications through in-house R \& D and through collaboration with overseas aerospace organizations and National Laboratories covering a wide spectrum including glass/carbon/kevlar fibre reinforced plastics, metal and Nomex honeycomb sandwich structures, laminated composites, metal matrix composites and metallo-ceramic composites.
\end{abstract}

Keywords. Polymer composites; honeycomb sandwich structures; metal matrix composites; glass/carbon/kevlar fibre reinforced plastics; metallo-ceramic composites.

\section{Introduction}

Composites are taking an important place in the manufacture of civil and military aircraft as they provide unique design opportunities to suit specific applications. Composite materials offer specific property advantages like higher modulus per unit weight (specific modulus) and higher strength per unit weight (specific strength), resistance to fatigue and corrosion, better thermal expansion characteristics and conductivity (for MMC) damping property and design flexibility. Research and development at HAL, in five distinct areas, namely polymer composites, sandwich structures, metal matrix composites, high temperature metal ceramic composite coatings and metallo-ceramic brake materials have led to the application of composite technology to specific areas in the manufacture of advanced aircraft, helicopters and jet engines.

$R$ \& $D$ in fibre reinforced plastics (FRP) started in the seventies for non-structural GFRP fairing for Cheetah and Chetak helicopters, has matured into a well established technology with production facilities for manufacture of primary load carrying structural parts using carbon, kevlar and glass fibre composites and also hybrid composites to make 'engineered composites components' to meet varied properties in different regions of the same part. Design and development of foam or metal/plastic honeycomb core sandwich structures has been an important activity in HAL. Several process technologies in this field and optimization studies have been made and production facilities established with capabilities to manufacture primary structures such as, floor boards for helicopters, aircraft and space vehicles and complex shaped and curved structures such as wing flaps, tail plane structures, side panel for fuselage and cockpit structures for helicopters. A related area of work is the development and application of bonded laminated structures.

$\mathrm{R} \& \mathrm{D}$ in metal matrix composites taken up at HAL has been mainly in the areas of aluminium alloy-SiC and magnesium alloy-SiC composites for structural applications. Metallo-ceramic composites and resin-fibre-ceramic composites have been developed as friction material for aircraft brakes. Another area of research at 
HAL in this field is the metallo-ceramic composite coatings on surface of jet engine components to protect against high temperature erosion and water. $\mathbf{A}$ number of such coatings have been established using electrochemical deposition, plasma coating and diamond jet coating techniques. Table 1 summarizes the development and application of composites in aircraft/helicopters and engines manufactured by HAL.

\section{Preliminary studies}

At HAL, preliminary studies on composites started in 1971 with the licensed manufacture of Cheetah and Chetak helicopters. The R \& D consisted of developing silane treated woven glass cloth to specifications, selection of polyester/epoxy resins, establishing process technology, testing and certification for airworthiness. The effect

Table 1. Composites in aircraft structures manufactured in India.

\begin{tabular}{|c|c|}
\hline $\begin{array}{l}\text { Glass fibre } \\
\text { reinforced plastics }\end{array}$ & $\begin{array}{l}\text { Chetak Helicopter - Fuselage fairings, doors } \\
\text { Ajeet Aircraft - Nose cone, fairings, electrical boxes, fin tip } \\
\text { Jaguar Aircraft - Wing leading edge, fin tip, Alpha boxes } \\
\text { MiG Aircraft - Nose cone, fairings } \\
\text { ALH Helicopter - Several structures and fairings }\end{array}$ \\
\hline $\begin{array}{l}\text { Foam and honeycomb } \\
\text { sandwich structures }\end{array}$ & $\begin{array}{l}\text { Cheetah and Chetak Helicopters - Floor boards } \\
\text { ALH - Fuselage structures } \\
\text { Jaguar - Front and fuselage structures, rudder, tail plane, flaps } \\
\text { and undercarriage doors } \\
\text { LCA - Front and fuselage structures, control surfaces and } \\
\text { undercarriage doors (proposed) }\end{array}$ \\
\hline $\begin{array}{l}\text { Durestos-asbestos } \\
\text { reinforced plastic }\end{array}$ & $\begin{array}{l}\text { Jaguar - Drop tanks } \\
\text { MiG - (proposed) }\end{array}$ \\
\hline $\begin{array}{l}\text { Carbon fibre } \\
\text { reinforced plastics } \\
\text { (CFRP) }\end{array}$ & $\begin{array}{l}\text { ALH - Rotor blades, front fuselage and centre fuselage structures } \\
\text { MiG - Fin tip, panels } \\
\text { LCA - Wings, undercarriage doors (proposed) }\end{array}$ \\
\hline Kevlar FRP & $\begin{array}{l}\text { ALH - Cockpit structure, inspection doors, centre fuselage } \\
\text { structures } \\
\text { Dornier-228 - Several secondary items }\end{array}$ \\
\hline $\begin{array}{l}\text { GFRP/CFRP/Kevlar } \\
\text { hybrids FRP }\end{array}$ & $\begin{array}{l}\text { ALH - Rotor blade, flex beam } \\
\text { LCA - Undercarriage doors (proposed) }\end{array}$ \\
\hline Laminated composites & ALH - Elastomeric bearings \\
\hline $\begin{array}{l}\text { Aluminium SiC } \\
\text { composites }\end{array}$ & LCA and undercarriage doors - (proposed) \\
\hline $\begin{array}{l}\text { Metallo-ceramic } \\
\text { composites }\end{array}$ & $\left.\begin{array}{l}\text { Kiran, Avro, MiG, AN-32 Jaguar, } \\
\text { Dornier, Cheetah/Chetak helicopters }\end{array}\right\} \begin{array}{l}\text { Brake pads } \\
\text { (friction material) }\end{array}$ \\
\hline $\begin{array}{l}\text { Resin-fibre-ceramic } \\
\text { composites }\end{array}$ & HPT-32 Piston engine trainer aircraft \\
\hline $\begin{array}{l}\text { Carbon-carbon } \\
\text { composites }\end{array}$ & LCA, MiG, ALH: Brakes (proposed) \\
\hline $\begin{array}{l}\text { Super alloy-ceramid } \\
\text { metal carbide } \\
\text { composite coatings }\end{array}$ & For surface protection of engine components \\
\hline
\end{tabular}


of treatment of glass cloth, plasticizing of resin, curing cycles etc. on properties such as strength, rigid polyurethane foam and type certification for adding rigidity to FRP structures were part of these early studies. These resulted in the establishment of a full fledged GFRP shop at HAL for making non-structural GFRP fairings for helicopter body, door and polyurethane foam filled sandwich structures including bonded rotor blades (figure 1).

\section{More recent work}

With the induction of the Jaguar aircraft into the defense services, HAL acquired several new technologies and augmented existing ones to cope with the steep advances in high technology areas. One significant technology is the honeycomb bonding and metal-to-metal adhesive bonding which led to series production of about eighty different varieties of honeycomb assemblies (figure 2). A few examples of technology development/improvements undertaken during this phase are given below.

\subsection{Honeycomb machining}

Technology for machining of complex shapes with curved surfaces have been established. Computer programmes for 5 Axis CNC machining for various shapes

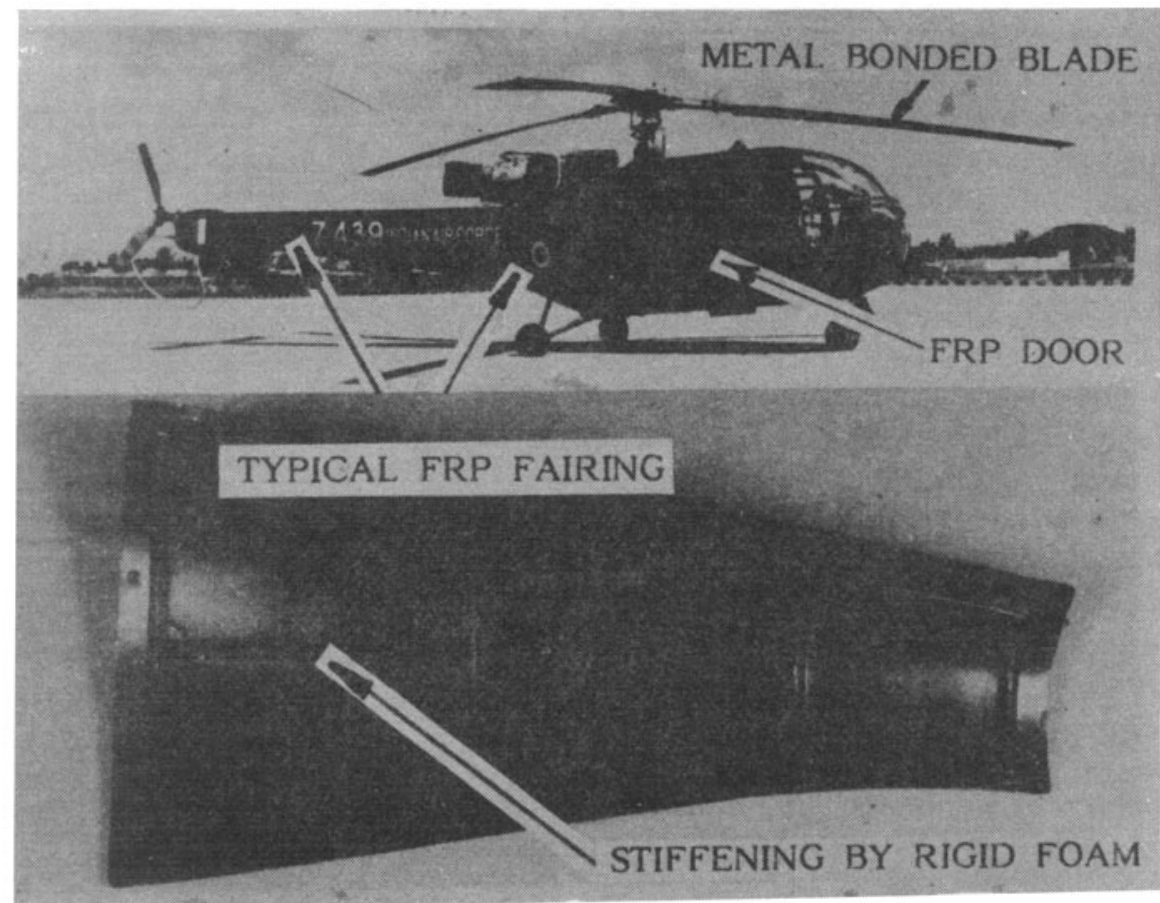

Figure 1. FRP applications in Chetak helicopter. 


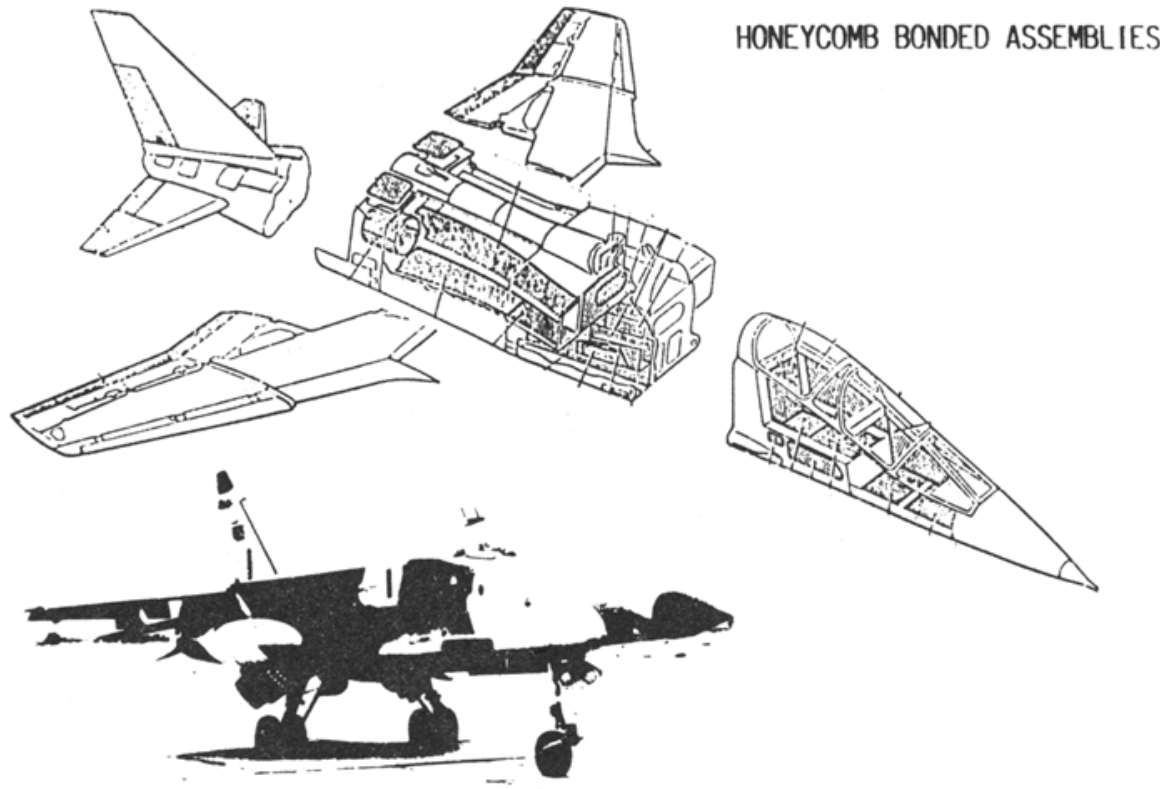

Figure 2. A view of honeycomb bonded structures in Jaguar.

have been developed. Vacuum application techniques for holding the work piece on to the machine bed and the development of suitable vacuum fixtures are important aspects of this technology development (figure 3). Cost effective techniques for machining of flat surfaces of soft cores such as plastic foams and honeycombs were developed along with the machinery and equipments indigenously. Also, for edge crushing and edge preparations. Honeycomb core crushing equipment and the technology were simultaneously developed (figure 4).

\subsection{Effect of surface preparation on the bonding strength}

Another area where technology improvements in bonding is carried out is in the optimum surface preparation of the metal/composite interface. Bonding surface is a very important area which controls the bond integrity. Surfaces with blasted, epoxy coated, pickled, anodized and epoxy spray were generated and experiments were carried out by bonding these surfaces with glass fibre, carbon and asbestos composites. Tensile lap shear specimens were made and tested for shear. Optimum surface preparations for each type of composites were developed. For carbon fibre composites ideal surface is anodized and epoxy primer coated; and for asbestos prepregs anodized surface gives excellent results.

\subsection{Floor boards and complex shaped sandwich structures}

Adopting the honeycomb bonding and composites technology concepts to other projects, several developments have been carried out. These include development 


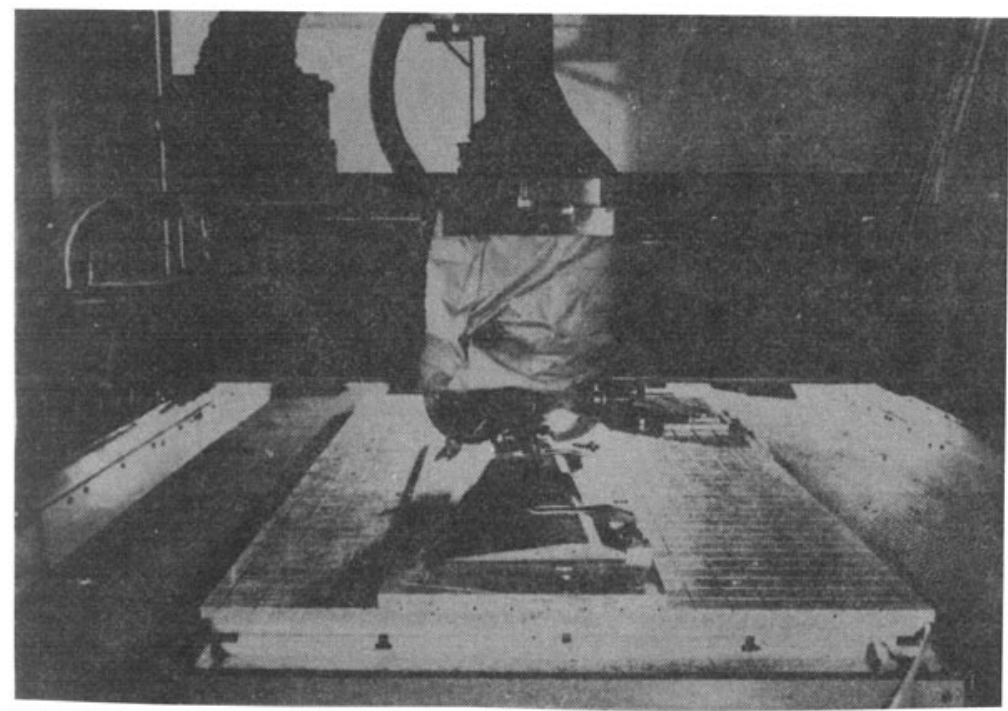

Figure 3. Five-axis $\mathrm{CNC}$ honeycomb core carver.

of honeycomb floor board for Chetak/Cheetah helicopters. ASLV and PSLV structures and now for the light helicopters. For curved shapes such as wing flaps, radars, side panels, etc., bonding technique for skin to core, vacuum bagging, prebonding and postbonding inspection techniques have been developed. Another significant development is paratrooper seat which consisted of a back rest made out of a carbon fibre composite box skin and a seat pan made out of carbon fibre skin and metal honeycomb core. In the development of various types of floor boards, the technologies of insitu bonding of locating points and load carrying members and also post bonding techniques for assemblies have been perfected. A typical honeycomb floor board and a fully assembled paratrooper seat are shown in figure 5.

\subsection{Radome structures}

Development of radome structures involved optimization of the skin and core thicknesses and bonding techniques to achieve the required electro-magnetic transparency. Technology for shaping and hot forming of non metallic honeycomb core "Nomex" was developed successfully to make sandwich structures for radomes. A large composite radome of diameter $7,300 \mathrm{~mm}$ was recently fabricated in HAL which is the largest composite structure produced in this country using glass impregnated advanced composites. Figure 6 gives some illustrations.

\subsection{Defect identification and characterization}

A number of test panels were fabricated using carbon fibre composites with various induced defects such as debonds, delamination and foreign object damages (FODs). Both straight and stepped panels were fabricated. The panels were subjected to 


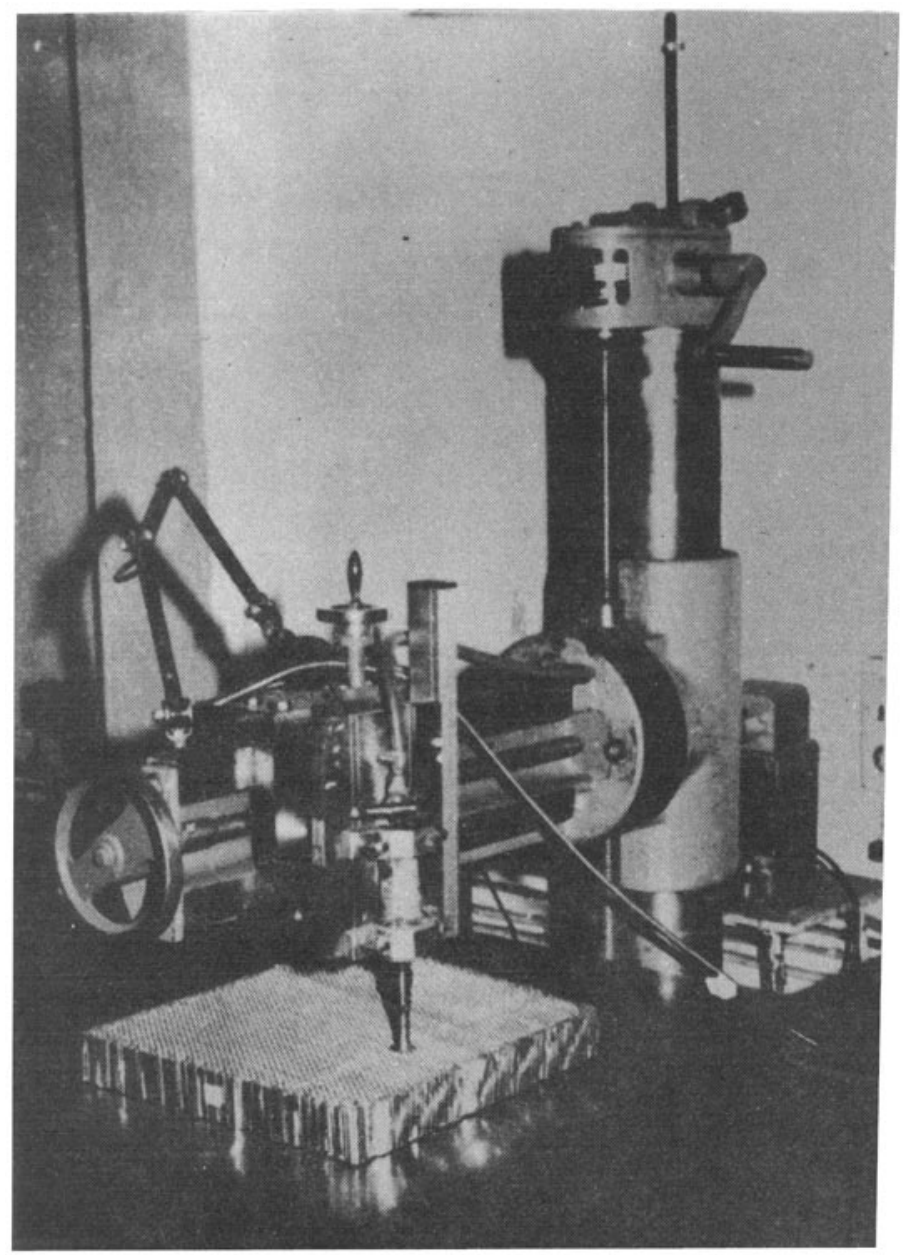

Figure 4. Honeycomb core machining equipment for flat surface machining.

inspection by NDT techniques, namely, ultrasonics (through transmission ultrasonic $\mathrm{C}$-scan and contact methods) and low energy $\mathrm{X}$-ray radiography. $\mathrm{C}$-scan revealed debond conditions induced by vidax and teflon but failed to detect the other defects namely non-metallic net and aluminium foil. Contact method showed varying levels of signal amplitudes, characteristic of each induced defect. Low energy X-ray radiography revealed all the defects except the defect induced by vidax. A combination of ultrasonics and $X$-ray radiography can identify all possible defects that may occur in a composite component. Also it is possible to characterize the defects using through transmission ultrasonics (figure 7). Improved methods of identification of defects using $\mathrm{C}$-scan multi-colour ultrasonic technique are also available. Based on the technology, a large ultrasonic C-scan has been designed and is under fabrication jointly by Aeronautical Development Agency, Hindustan Aeronautics Centre for Artificial Intelligence and Robotics and Vivace Sonics. 


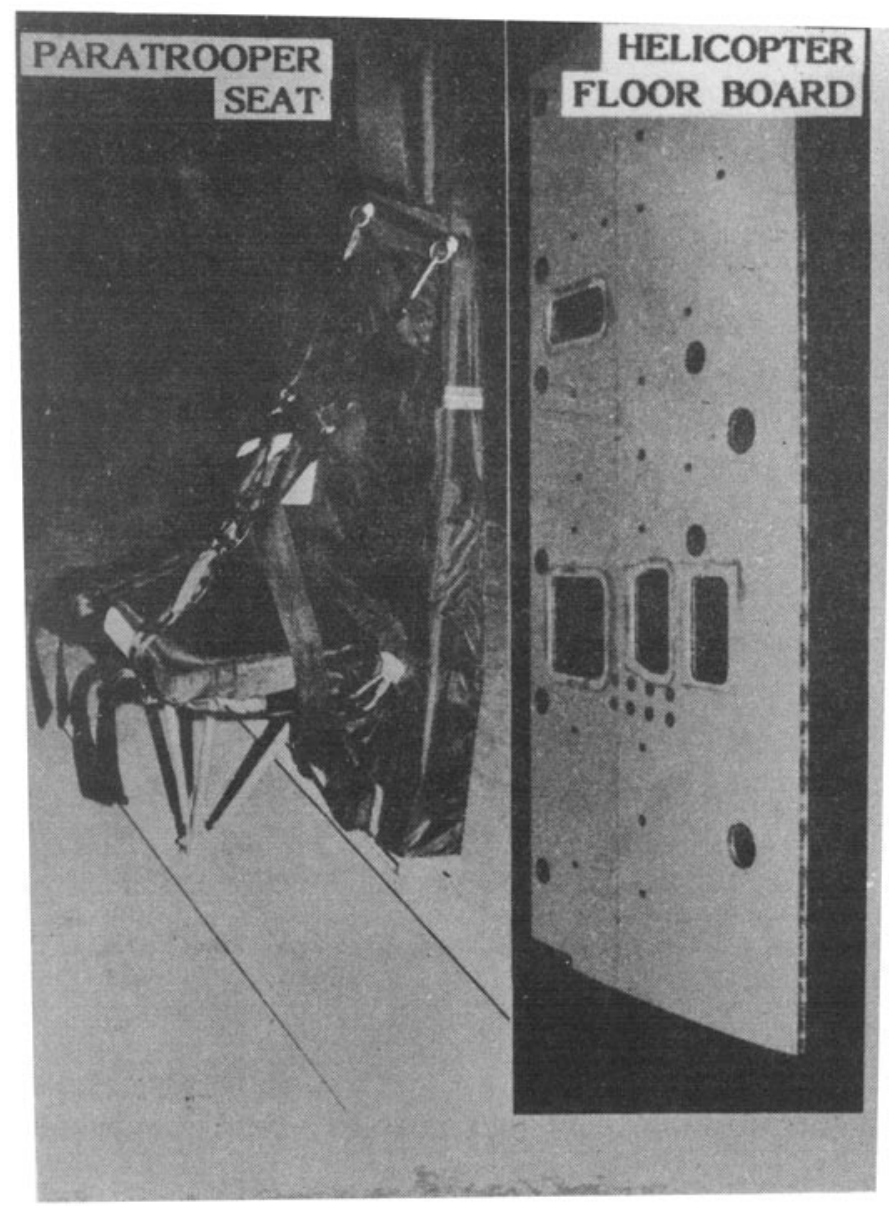

Figure 5. A typical floor board for helicopter applications and a paratrooper seat assembly for Dornier aircraft made from composites.

\subsection{Resin injection moulding}

Technology was developed for moulding fibre reinforced plastic components by injection moulding. Glass fibre cloth stitched to the shape required is inserted in the predesigned mould and resin is injected under pressure (figure 8). A large number of components have been produced for domestic and for export market.

\subsection{FRP pipes}

A unique technology for making complex shaped pipes in reinforced plastics has been developed by adopting the investment casting technique from the Foundry industry. Wax patterns are made and resin impregnated tapes are wound to build adequate thickness. After room temperature curing, the wax is melted out at $80^{\circ} \mathrm{C}$ in an oven followed by a post curing cycle at an elevated temperature. Production facilities have been established both for Indian and for export market (see figure 9). 


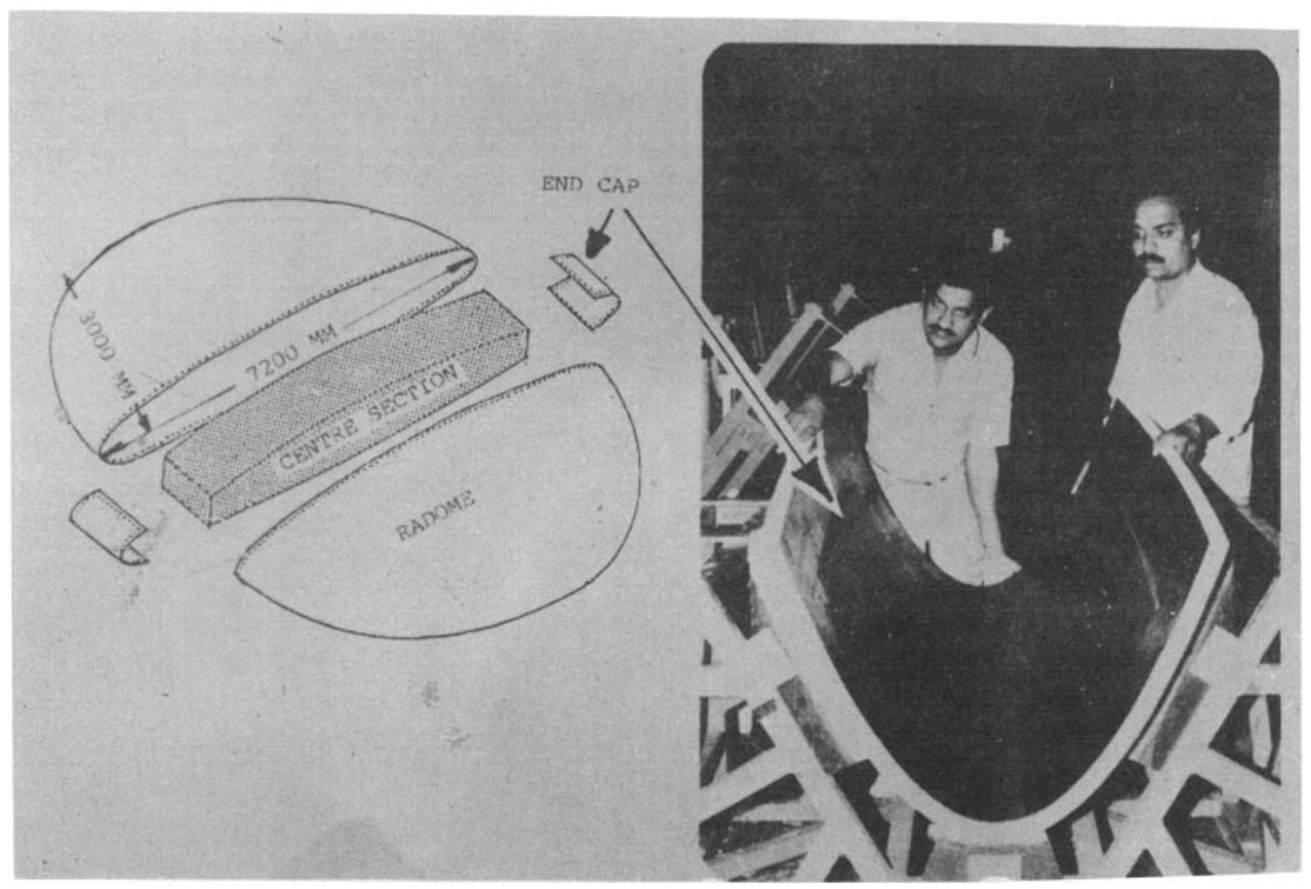

Figure 6. A schematic view of the complete arrangement of the composite radomes and a view of the end cap.

\section{Composites for advanced light helicopter and light combat aircraft}

The Advanced Light Helicopter (ALH) and Light Combat Aircraft (LCA) make extensive use of composites (figures 10 and 11). Carbon, kevlar, glass reinforced plastics and their hybrids as well as metal and nomex, honeycomb sandwich structures are extensively used. An example of excellence in this field is the single piece moulded cockpit structure (carbon/kevlar) for ALH (figure 12). The main rotor blade for ALH is an illustration" of the maturity in the design, development and manufacture of a composite of composites (figure 13). The honeycomb core and glass/carbon fibre skin for the blade aerofoil give desired strength and rigidity, the quantum and orientation of fibres give required directional property and fatigue resistance; and the flex collar provide adequate flexibility (by hybridization to take care of lead/lag/flap and torsion and meet the design requirement of hingeless rotor). LCA envisages utilisation of several advanced composite structures, the most significant among them being the carbon fibre composite wing under development by a national team of designers, scientists and technologists from HAL, ADA and NAL.

An important development in making these components has been the development of composite tooling itself. Tools are developed through master model techniques using glass, carbon, epoxy and wet layup techniques. These are initially cured under room temperature and then post-cured at elevated temperature to avoid 


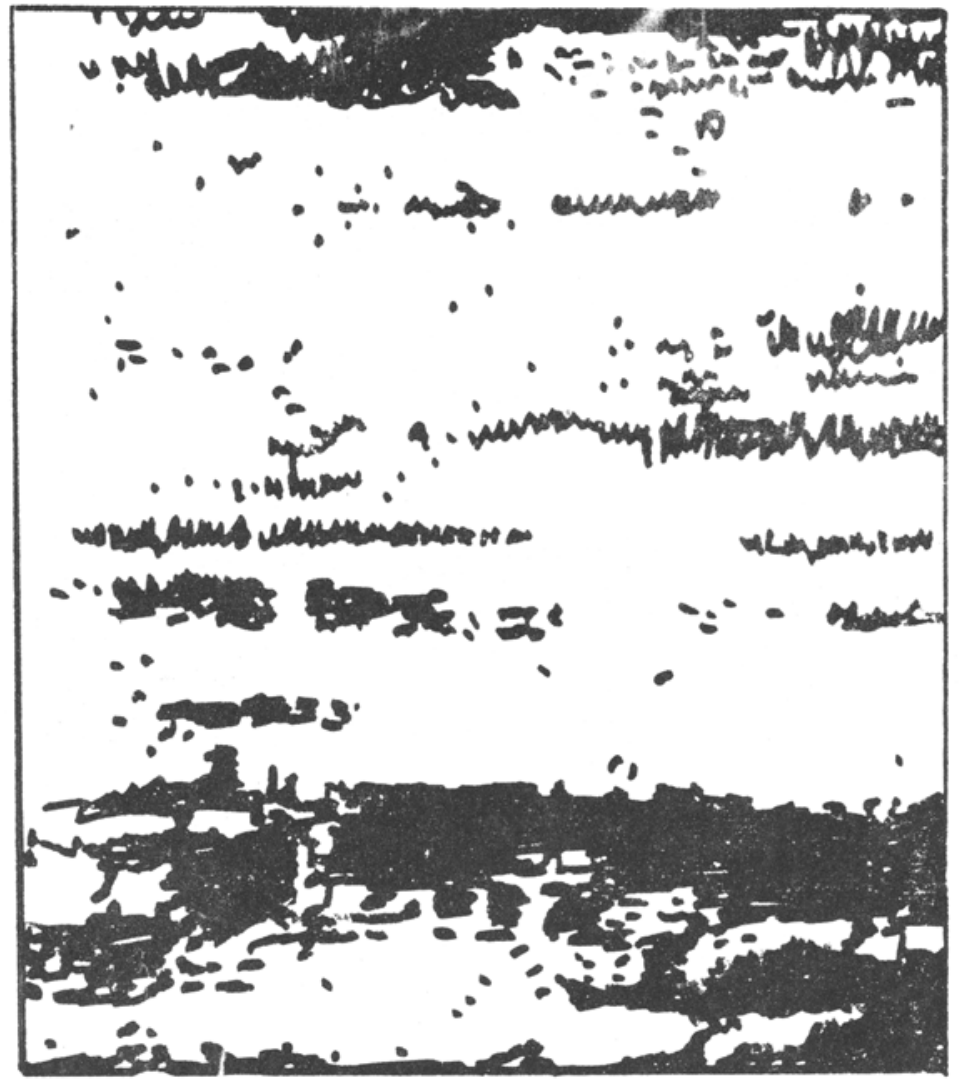

Figure 7. A C-scan ultrasonic plot showing the bonding integrity variations. Blank shows maximum integrity and dark areas show medium integrity.

warpage and for increased strength. Composite tooling technology apart from giving more dimensional acccuracy is also a cost effective solution as otherwise these large complex tools would have required 5 axis CNC machining for metal moulds.

Plywood is perhaps the earliest example of laminated structures used in some of the older generation of aircraft. More advanced laminated composites are emerging with the advancement in bonding technology and high strength adhesives. It is proposed to use some of these for specific application in LCA and ALH and research and development has been taken up in some areas. High strength aluminium alloy thin sheet and carbon/kevlar/glass fibre reinforced plastic laminated structures for structural applications is one area of work. Metal/rubber laminated structures for elastomeric bearings is another area.

\section{Metal matrix composites}

A number of compositions of aluminium alloy 6061 and alloy 7010 with varying percentage of $\mathrm{SiC}$ particulates have been prepared and evaluated providing a range 


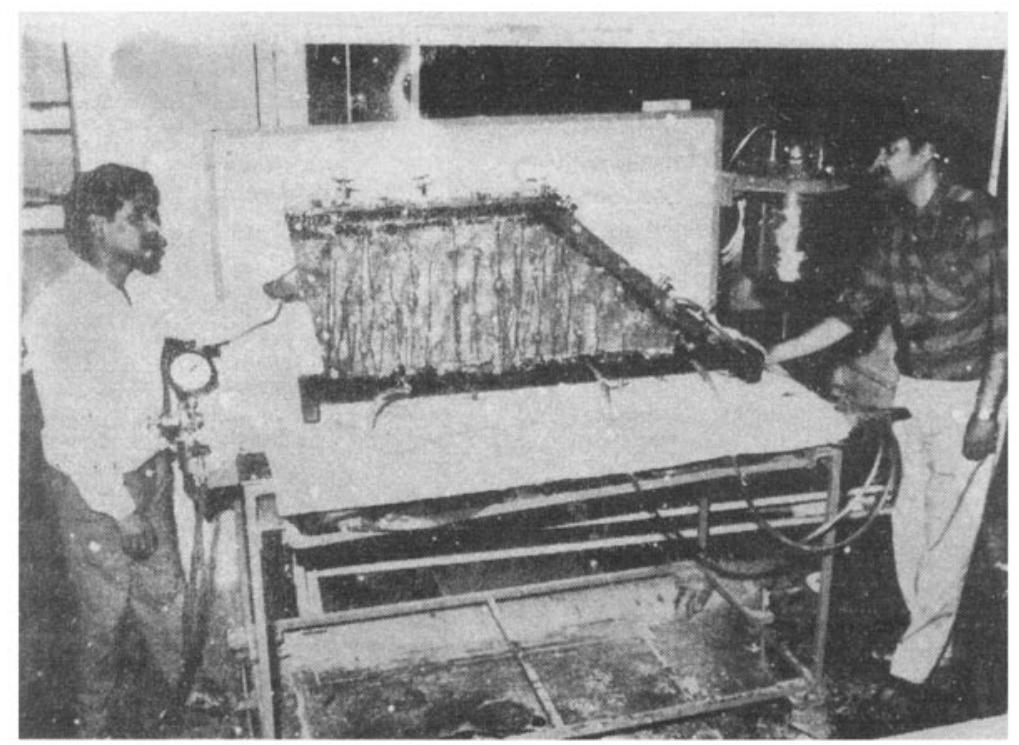

Figure 8. Resin injection moulding along with nould set-up.

of high strength and high modulus composites. MMC of this type have been produced both by foundry technique and powder metallurgy followed by consolidation through forging/extrusion. Technology has been established and hot press billets up to $150 \mathrm{~mm}$ dia. and extrusions up to $60 \mathrm{~mm}$ dia. have been made. Typical products planned are, aircraft forgings, low thermal expansion missile components, high modulus space vehicle components, etc. Shaped extrusions including tubes have been prepared in collaboration with National Physical Laboratory, Materials Division and Regional Research Laboratory, Trivandrum (figure 14). Recently the work on magnesium $\mathrm{SiC}$ composites using foundry route has also been taken up.

\section{Metallo-ceramic and resin-fibre-ceramic composite brake material}

Aircraft brake materials are essentially resin, copper or iron based with various other metallic, non-metallic and ceramic ingredients to provide a combination of a variety of properties required for aircraft brakes. Carbon-carbon fibre composite is the most recent and advanced brake material. When an aircraft lands and progressively comes to a halt, the kinetic energy is converted into heat energy by friction by the rubbing of surfaces of the brake material. Hence the brake material should have high friction coefficient and at the same time good wear resistance. The heat generated has to be dissipated and, therefore, it should have good thermal conductivity besides high specific heat to reduce rise in temperature. It should also have anti-seizure properties and high temperature strength and hardness. Design and development starts with an analysis of the braking requirements, namely the energy to be absorbed and the heat generated, based on which specific values are derived for coefficient of friction, thermal conductivity, acceptable wear, anti-seizure property and high temperature strength and hardness etc. Composition of the composite is 


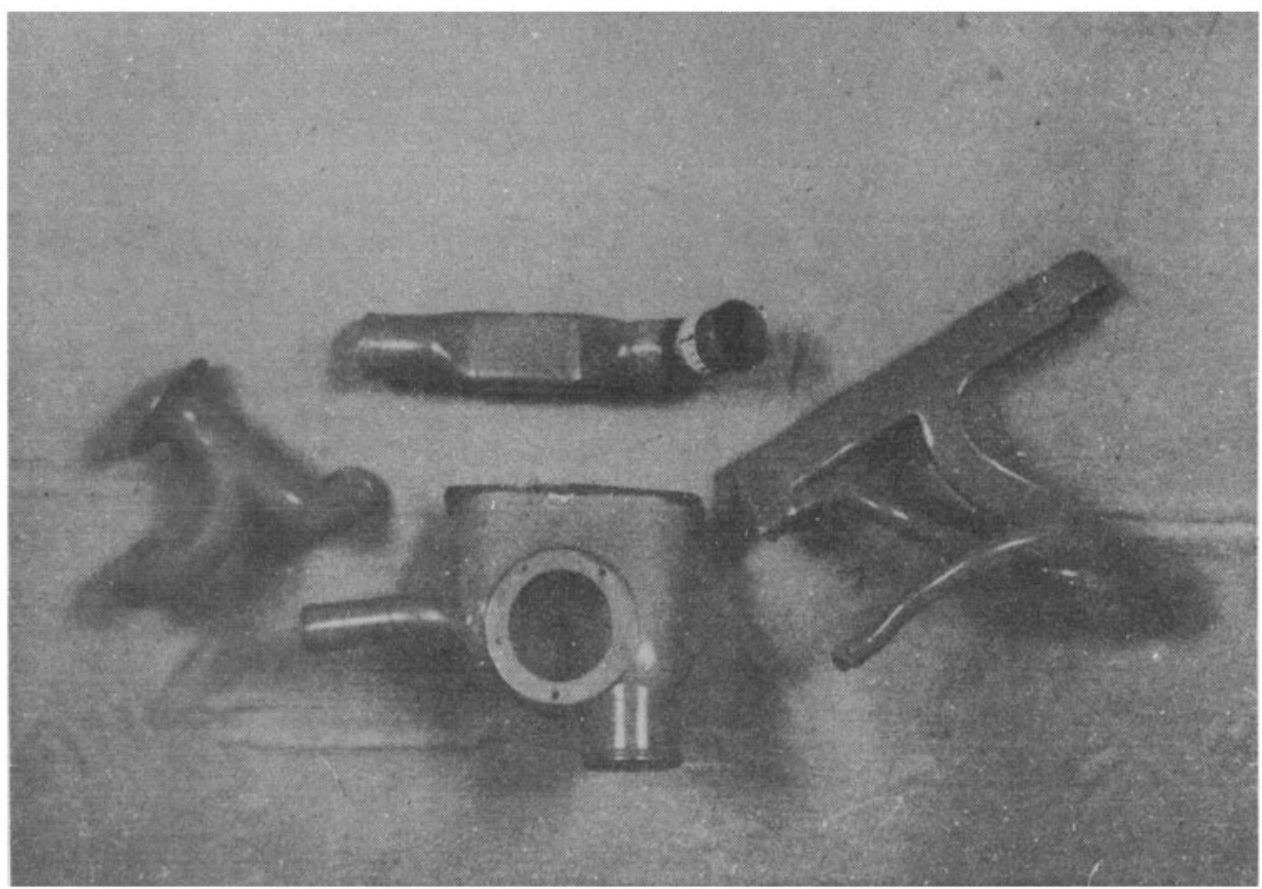

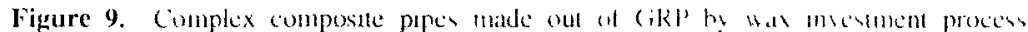

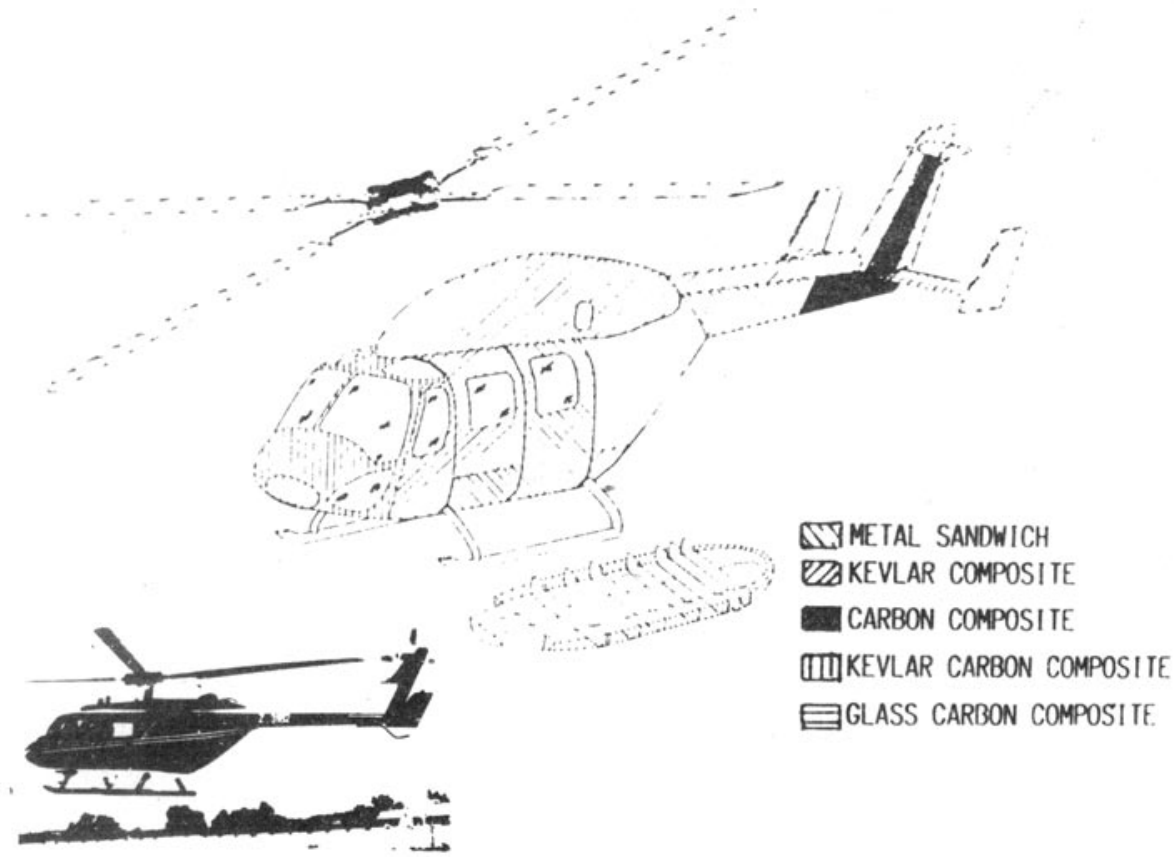

Figure 10. Advanced light helicoplic and major areas where composites are made use of. 


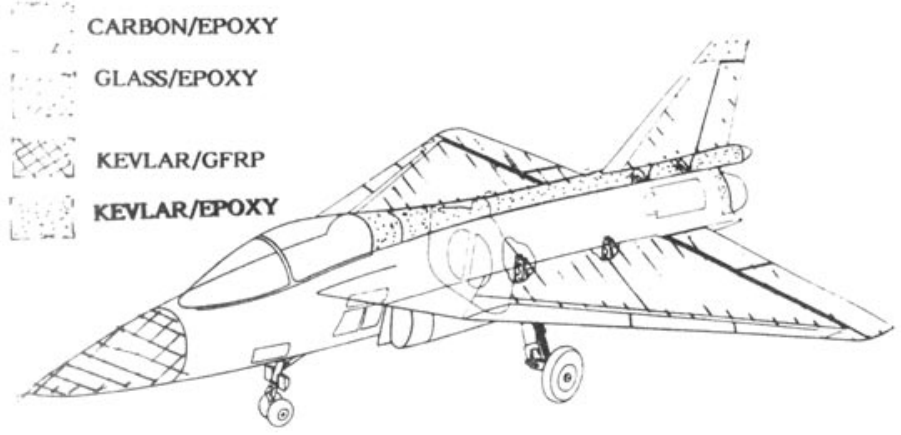

Figure 11. Light combat aircraft. Composite materials used on the aircraft are highlighted.

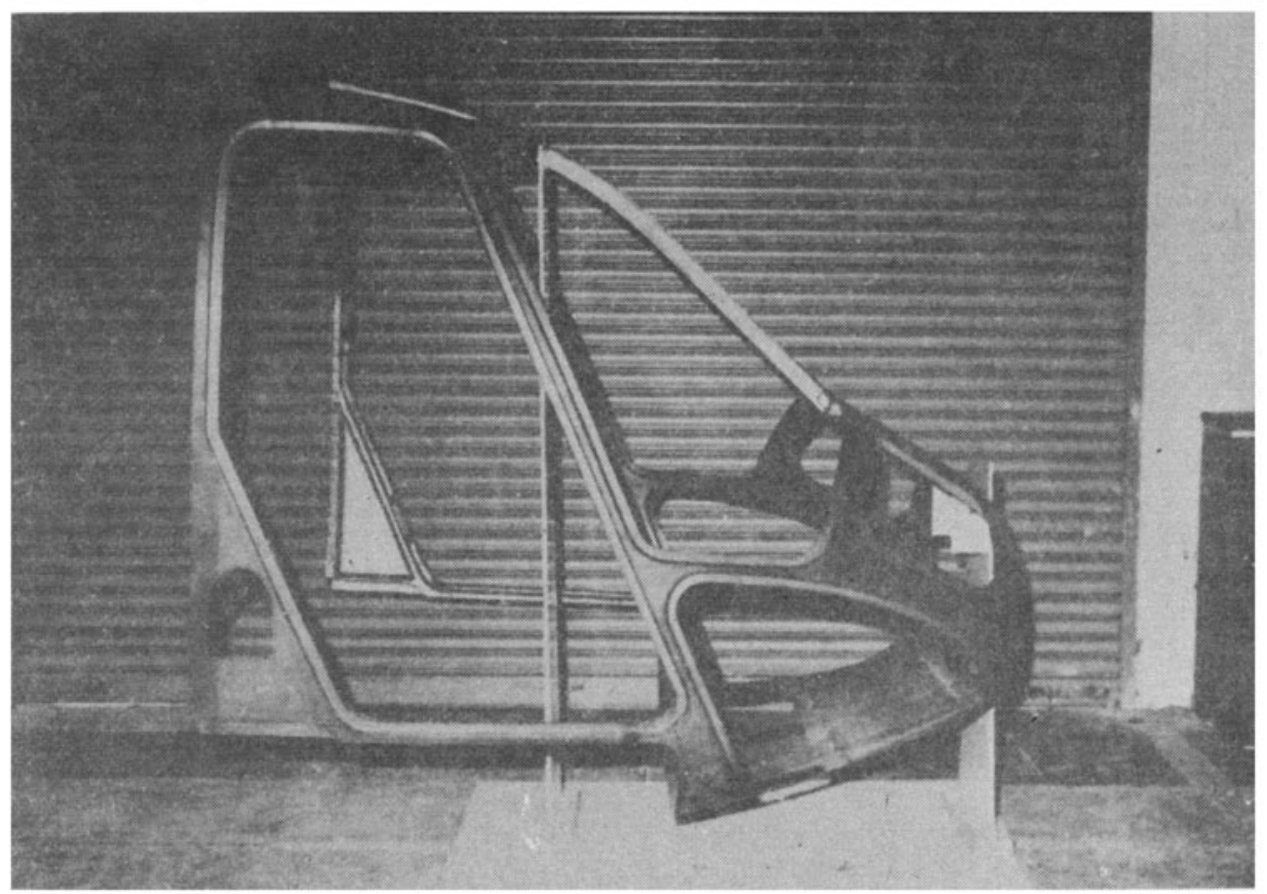

Figure 12. Cockpit structure for ALH-single piece compostte component.

then selected based on statistically designed experiments to optimise composition and process parameters to meet these property requirements. The process route followed for a typical metallo-ceramic brake pad is shown in figure 15. For resin based brake pads low energy brake application used in piston engine aircraft, the process followed is by mixing the ingredients with resin and casting the resin to shape followed by finishing with machining and grinding operation. Working in close co-operation with Defence Metallurgical Research Laboratory, Hyderabad, and 


\section{COMPOSITE ROTOR BLADE}
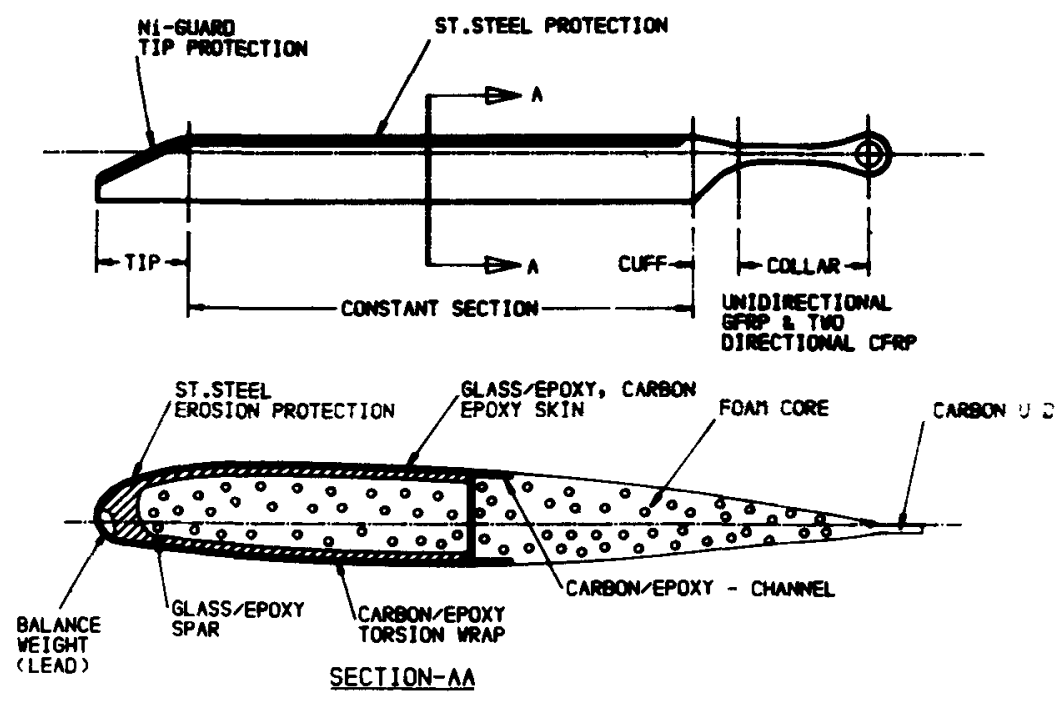

Figure 13. Composite main rotor blade and its section for an advanced helicopter.

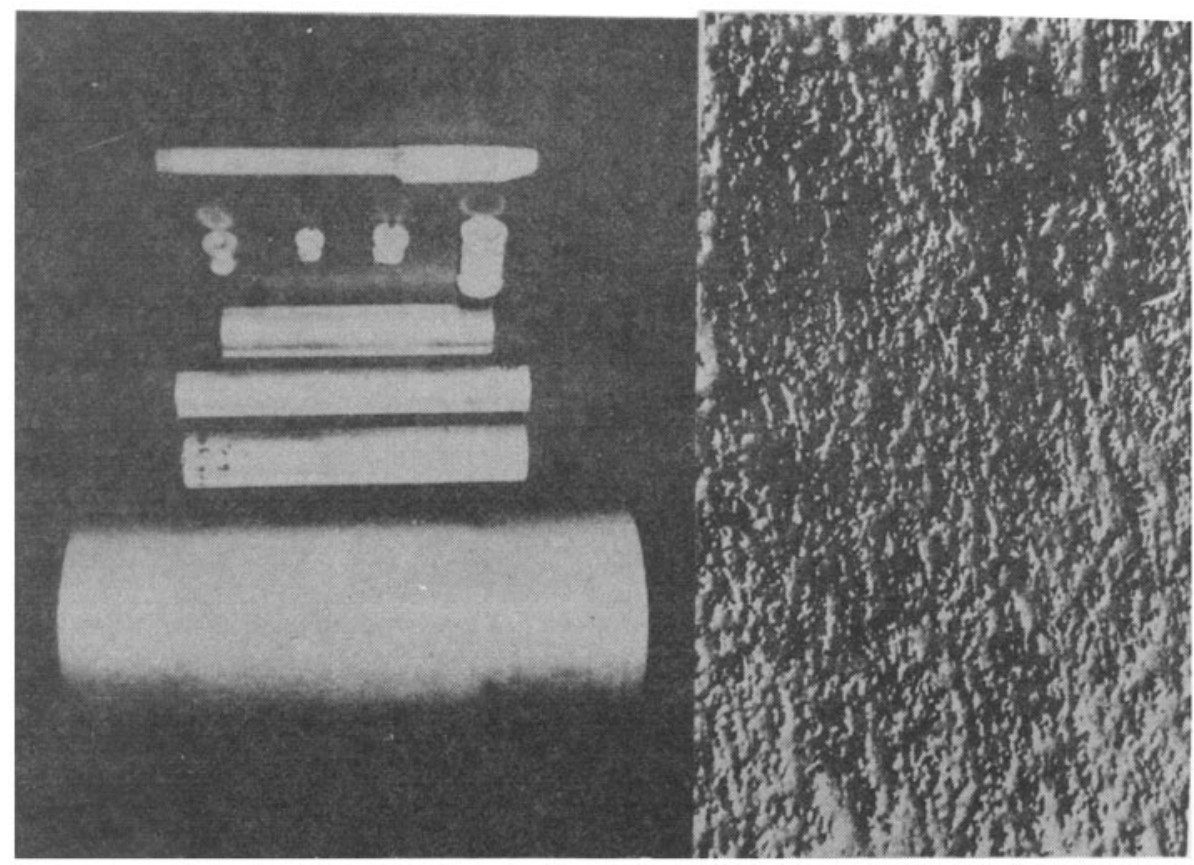

Figure 14. Metal matrix composites develcped in-house. Typical microstructure is also shown. 


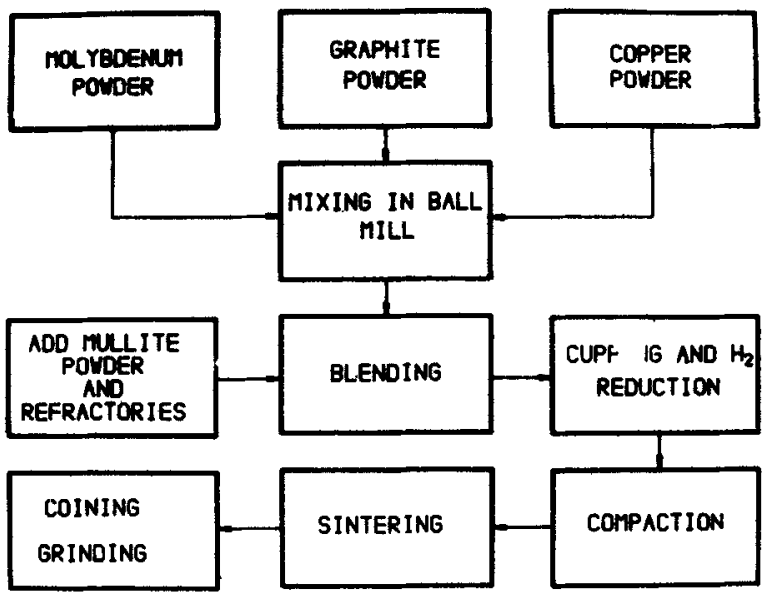

Figure 15. P/M process for manufacture of copper based brake pad segments.

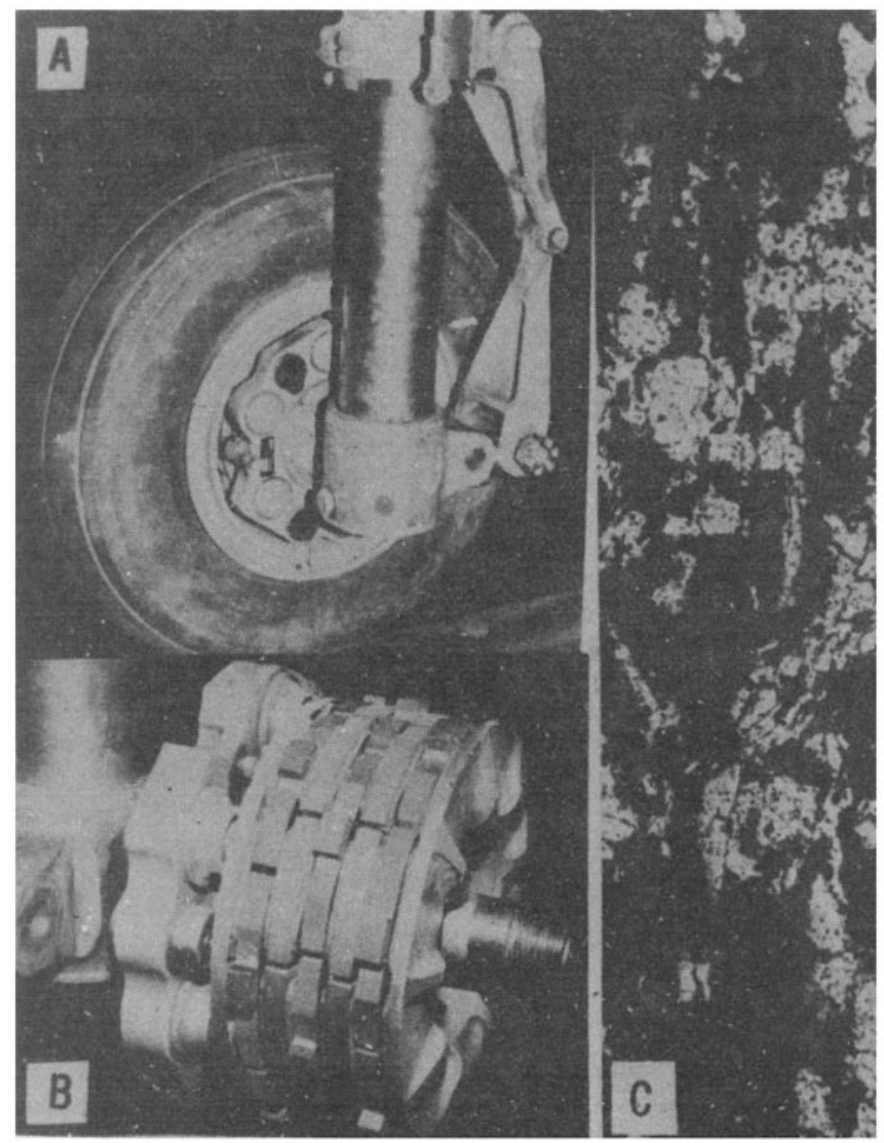

Figure 16. Brake pad development for a fighter aircraft landing gear. (A) landing gear assembly, (B) brake pad assembly and (C) a typical microstructure. 


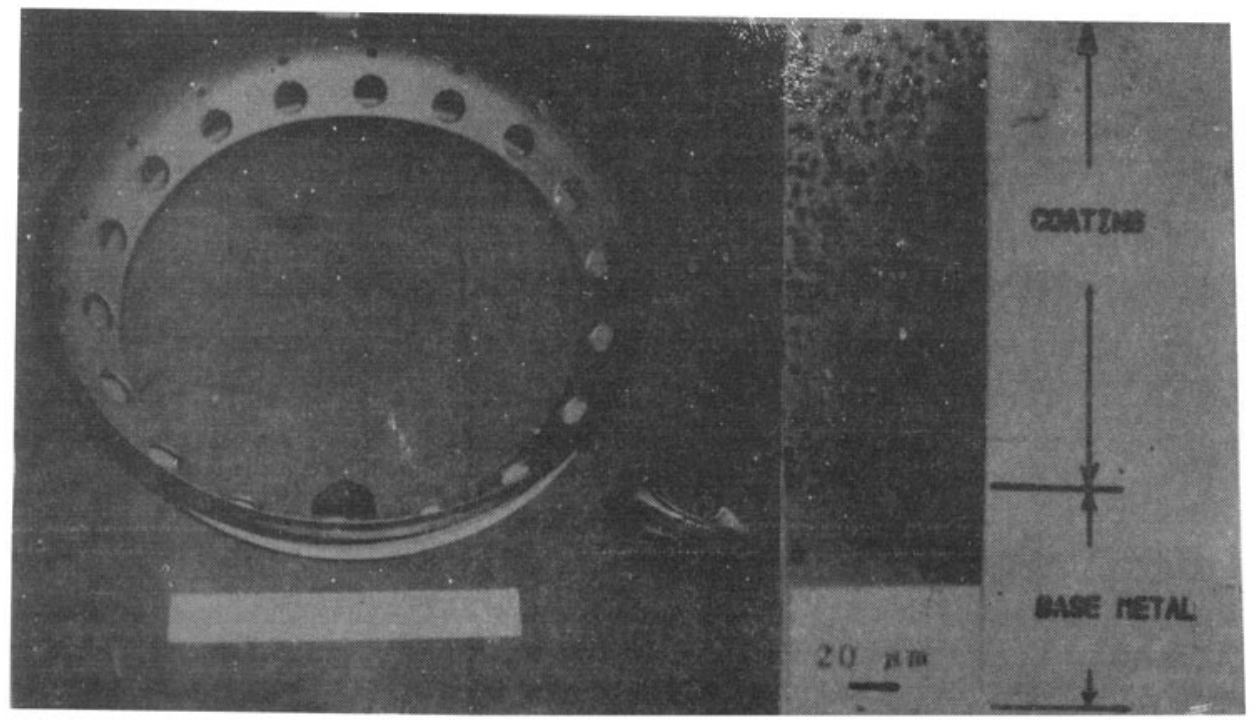

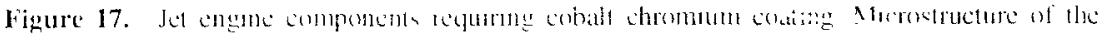
criblung bown on right.

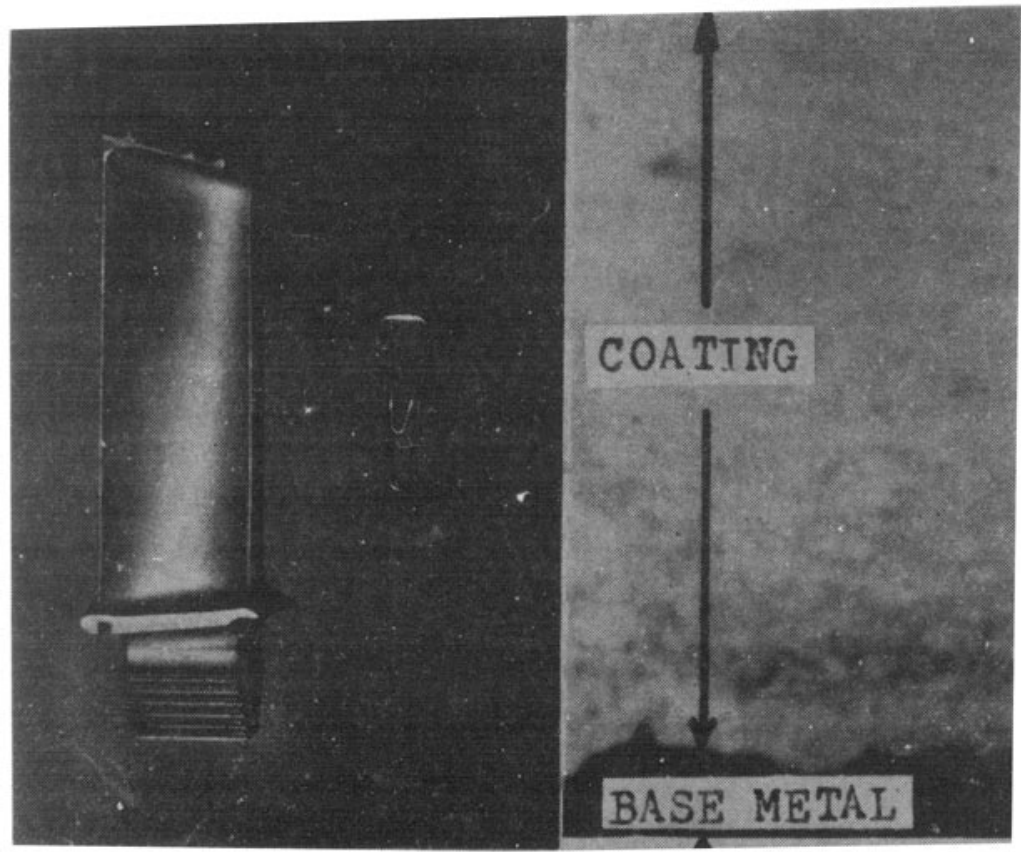

Figure 18. Jet engine turbine blade with chromium carbide coating. Microstructure of the coating shown on right. 
IIT, Madras, HAL has developed and established technology for various types of aircraft brakes required for the military/cargo/passenger aircraft. Figure 16 shows a typical example.

\section{Metallo-ceramic composite coatings}

In order to increase the life of critical engine components for high performance jet engines, it is necessary to engineer the surface of the parts to provide high temperature corrosion and wear resistance. Metallo-ceramic composites using super alloys as matrix material are essentially employed as excellent coatings for this purpose. Several such composite coatings have been developed using plasma, Detonation gun (D-gun), electroplating and diamond jet techniques. Cobalt-chromium carbide composite is one such coating which is extensively used for hot end components of jet engines. Research and development was taken up to develop a process of co-deposition of cobalt and chromium carbide on to components. This has been successfully accomplished and production facilities are established. The essence of the technology development consists of designing a plating equipment incorporating an oscillatory perforated plate agitator to keep the fine chromium carbide particles in suspension so that they will be picked up along with cobalt ions and deposited during the electroplating process. A series of carefully planned experiments optimize the design for the same. A few examples of components and microstructure are shown in figure 17. Another example is a composite coating consisting of $75 \%$ chromium carbide $+25 \%$ nickel-chromium developed for use on Adour engine low pressure turbine blades (figure 18). In this case, the coating was deposited using a D-gun available at the Advanced Research Centre for Power Metallurgy, Defence Metallurgical Research Laboratory, Hyderabad. R \& D using diamond jet coating techniques is also in progress for metal ceramic coatings.

\section{Conclusions}

Hindustan Aeronautics Limited has established a sound technology base and production facilities for composite materials for aerospace applications through in-house research and development and through collaboration with overseas aerospace organisations and national laboratories. The range of expertise and products cover a wide spectrum including glass/carbon/kevlar fibre reinforced plastics, metal and nomex honeycomb sandwich structures, laminated composites, metal matrix composites and metal-ceramic composites for aerospace structures, aircraft brake materials and for coating of jet engine components. 